\title{
Strengthening Primary Health Care Through Asha Workers: A Novel Approach in India
}

\author{
Mane Abhay $B^{1 *}$ and Khandekar Sanjay $\mathbf{V}^{2}$
}

${ }^{1}$ Department of Community Medicine, Smt. Kashibai Navale Medical College, Pune, Maharashtra, India

${ }^{2}$ Department of Community Medicine, Ashwini Rural Medical College, Solapur, Maharashtra, India

\begin{abstract}
A primary health care-based health system should ensure universal coverage and access to services that are both equity-enhanced and acceptable to the population. Accredited Social Health Activist being the grass root level worker, the success of National Rural Health Mission in India depends on how efficiently is ASHA able to perform. ASHA plays an important role in reaching primary health to rural areas. She is an inevitable component in bringing health services to the grass root level by creating awareness on health and mobilizing the community towards local health planning. This has resulted into increased utilization of maternal and child health services. She has an important role in motivating people to use existing health care services and acts as a link between community and the health care system. She collaborates with local self governments in addressing the health needs of the society. After implementation of the programme, some health indicators have shown decline like Maternal Mortality Ratio, Infant Mortality Rate and Total fertility Rate. With the involvement of ASHA, the country has been making remarkable strides in the improvement of maternal health. ASHA's have become a backbone of National Rural Health Mission and have become an integral part of social life in the villages of India. From the perspective of the shortage of human resources for primary health care in the country, ASHAs are an important resource complementing the health system and facilitating efforts to achieve the Millennium Development Goals.
\end{abstract}

Keywords: Primary health care; ASHA; MMR; IMR; Institutional delivery

\section{Introduction}

Social development of a nation is dependent on the health of its population. India has made considerable progress towards the reduction of Maternal Mortality Ratio (MMR) and Infant Mortality Rate (IMR), the current pace of decline was not sufficient to achieve the goals and targets by 2015 under Millennium Developmental Goals (MDG). Maternal and newborn health indicators in India were not nearly low enough to achieve national or global targets. According to a WHO Inter-agency report [1] on Trends in Maternal Mortality from 1990 to 2010 , there were 287000 maternal deaths in 2010 with developing countries accounting $85 \%$ of those deaths, and $19 \%$ of maternal deaths in India.

National Rural Health Mission (NRHM) was launched on April 12, 2005 to correct the deficiencies of the health system, increase spending on health and to provide good decentralized healthcare [2]. A core strategy was to strengthen the existing Primary Health Centres (PHCs) and Community Health Centres (CHCs) in terms of both infrastructure and human resources, with a view to achieving a number of goals to reduce infant and maternal mortality as well as the incidence of several communicable diseases. NRHM had been envisaged as focal point of all the programs targeted to improve the health of rural people in India with a focus of involving people or community in administering health measures. One of the main core strategies suggested under the NRHM was the creation of the much touted Accredited Social Health Activists (ASHA) to strengthen the decentralized village and district level health planning and management. Since Subcentres were serving much larger population than they were expected to and Auxiliary Nurse Midwife (ANM) were heavily over worked, one of the core strategies of NRHM was to promote access to improved health care at household level through ASHA. The NRHM Program worked by providing every village in India with a trained female community health activist volunteer. Each of these community health workers, referred to as ASHA, is between the ages of 24-45 and literate, with a minimum level of 8 years of formal education. Each ASHA underwent a regular and periodic training. This enabled them to empower women in their own communities to make healthy decisions and understand determinants of health, such as nutrition, sanitation and hygiene. The ASHA usually fulfills 10 critical functions for the community where she operates [3] is as follows-

1. Create awareness and provide information to community

2. Counsel mothers on birth preparedness, safe delivery, feeding practices, immunization, family planning, RTI, etc

3. Facilitate community access to health care and health facilities

4. Accompany pregnant women and children to health facility

5. Provide care for minor ailments

6. Act as depot holder for ORS, IFA, DDK, Oral pills, condoms

7. Provider of DOTS

8. Newborn care and treatment of childhood illness (IMNCI)

9. Inform birth and deaths, disease outbreaks

10. Construction of Toilets for TSC (Total Sanitation Campaign) -Not included in UP state policy for ASHAs

*Corresponding author: Dr. Mane Abhay B, Department of Community Medicine Smt. Kashibai Navale Medical College, Narhe, Pune, Maharashtra, India, Tel: 8975008663; E-mail: drabmane@yahoo.co.in

Received December 23, 2013; Accepted January 21, 2014; Published January 27, 2014

Citation: Mane Abhay B, Khandekar Sanjay V (2014) Strengthening Primary Health Care Through Asha Workers: A Novel Approach in India. Primary Health Care 4: 149. doi:10.4172/2167-1079.1000149

Copyright: @ 2014 Mane Abhay B, et al. This is an open-access article distributed under the terms of the Creative Commons Attribution License, which permits unrestricted use, distribution, and reproduction in any medium, provided the original author and source are credited. 
The health focus for ASHAs is diverse but all related to women's health and maternal health. For example, each ASHA was adequately prepared to provide advice on labor and delivery, breast-feeding, immunizations, contraception, prevention of common infections, and care for newborns and young children. They are also a resource for tangible items like oral rehydration therapy(ORT), iron folic acid tablets, and contraceptive materials, items that are invaluable to newborn and child health, maternal health, and family planning methods. Although each ASHA is working on a volunteer basis, there are incentives for positive health indicators. For example, for each woman who delivers a child in a hospital, the ASHA is reimbursed 600 Rupees $(\$ 11.70$ USD); the mother who delivers at a hospital is reimbursed 1400 Rupees (\$27.30 USD). There are also incentives for getting children timely and complete immunization. The involvement of ASHA has strengthened the primary health care in India by addressing the key issues of health disparity by keeping in mind the following principles of primary health care-

\section{Equitable distribution}

The availability of manpower is one of the important prerequisite for the efficient functioning of the Rural Health services. As of 2012, $3.8 \%$ of the Sub Centers were without a Female Health Worker / ANM and $51.6 \%$ Sub Centers were without a Male Health Worker. 2.7\% Subcentres were without Female Health Worker / ANM as well as Male Health Worker [4]. Hence one ASHA was chosen for every village with a population of 1000 to act as the interface between the community and the public health system and was accountable to the Gram Panchayat (Local Self Government). At present the number of ASHA workers recruited is more than 0.8 million [5] as shown in Figure 1. The NRHM's ASHA workers made significant contributions to expanding access to healthcare in rural and poor communities across India [6]. To address the challenge of accessibility and provision of health services in geographically difficult areas, ASHA plus programme was initiated with flexible population coverage. Definite improvement was seen in the distant and underserved villages in the areas of early registration of pregnancy, antenatal care, and institutional delivery, as per the rapid assessment results from Uttarakhand, India [7]. A study conducted by the Columbia University in 4 states in India [8] indicates that, an ASHA in UP covers approximately 23 households per week. Hence the primary health care is made accessible and available to the rural areas by these ASHA workers.

\section{Community participation}

ASHA workers were selected from the village in which she stays with a formal education upto $8^{\text {th }}$ class by the selection committee. She is part of the community in which she will be working follows one of the principles of primary health care as community participation. She was given an induction training of 23 days in sessions with periodic trainings. Selected from the village itself and accountable to it, the ASHAs serve as a liaison between the community and the public health system [9].

\section{Inter-sectoral co-ordination}

All ASHAs are involved in the Village Health and Sanitation Committee of the Panchayat either as members or as special invitees (depending on the practice adopted by the State). ASHAs may coordinate with Gram Panchayat in developing the village health plan. They are coordinating with the anganwadi worker to complete the village health register. She is organizing monthly health and nutrition days in co-ordination with the anganwadi worker and ANM.

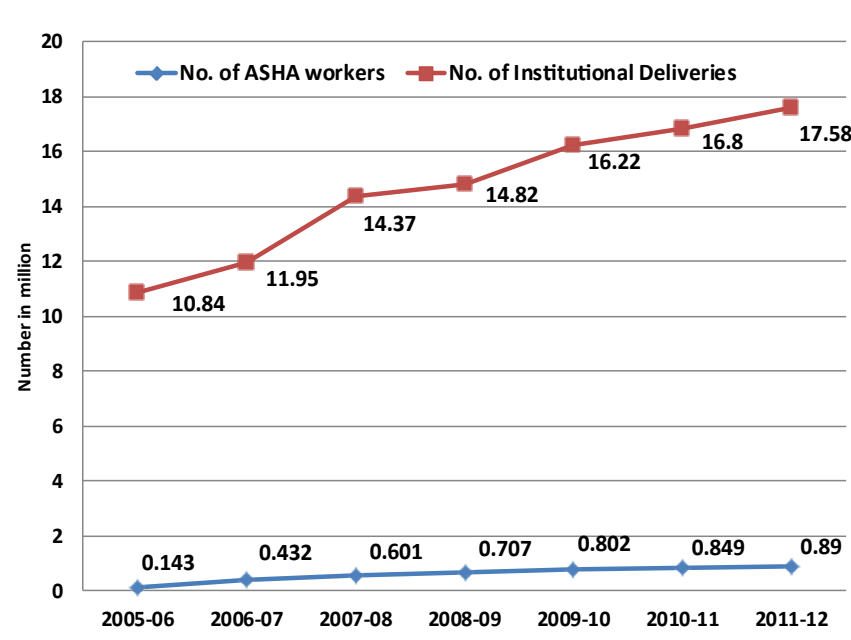

Figure 1: Graph showing rise in institutional deliveries with recruitment of ASHA workers under NRHM in India.

\section{Performance evaluation of ASHA workers}

Many evaluations have been done on the performance of ASHA workers that unanimously observed the role of them in strengthening the primary health care in India $[10,11]$. After the introduction of ASHA workers under the NRHM from 2005 to 2006 in India, utilization of healthcare services at the peripheral level has improved [12]. According to a report released by the State Institute of Health \& Family Welfare, Rajasthan, ASHA workers have brought an increase of $80.7 \%$ in institutional deliveries [13]. In a rapid appraisal of the ASHA scheme in Uttar Pradesh [14], it was observed that $70 \%$ of institutional deliveries were motivated and facilitated by the ASHA's. Review of preliminary evidence suggests that ASHA's have played a critical role in improving delivery of targeted services, and ultimately in health outcomes. For example, a 2008 United Nations Population Fund (UNFPA) assessment of the NRHM programme [15] in Bihar, Madhya Pradesh, Orissa, Rajasthan, and Uttar Pradesh revealed that institutional delivery rates had increased from about 12 percent in 1992-93 to about 55 percent in 2008. The increase in number of institutional deliveries is also shown in Figure 1. According to another study [16] linking ASHAs to maternal and infant care (including the attendance of home deliveries, caring for the infant at birth, conducting home visits and supporting mothers in newborn care, monitoring the newborns, and managing newborn sicknesses), the neonatal mortality rate declined about 70 percent between 1993 and 2003 in comparison to control areas [14]. In a study conducted in Uttar Pradesh observed that $59 \%$ of the immunization activities were facilitated by ASHA workers. In another study [17] from Jharkhand, 93.8\% of ASHA workers advised parents of malnourished children to take them daily to the Anganwadi Centre. In a study by Singh et al. [18] found that ASHA's were able to connect and convince women to utilize antenatal and postnatal services. The study from Kerala [19] showed that ASHAs were involved in the Gramsabhas for decisions related to the health needs of the community. ASHAs role is commendable in addressing the local health needs and making policy level changes in the local self Governments. ASHA workers also worked towards strengthening eye health care and education in the area of Bhagalpur District of Bihar [20]. A new scheme was recently launched to incentivize ASHA for providing Home Based Newborn Care in which they will make home visits to all newborns according to specified schedule up to 42 days of life. 
Citation: Mane Abhay B, Khandekar Sanjay V (2014) Strengthening Primary Health Care Through Asha Workers: A Novel Approach in India. Primary Health Care 4: 149. doi:10.4172/2167-1079.1000149

\section{Health outcomes [4] after ASHA programme}

Infant Mortality Rate (IMR): A significant decline has been achieved in IMR from 58 per 1000 live births in 2005 to 30 per 1000 live births in 2012. 5 states have achieved the target of less than 21 and 12 states are in the range of 30-40.

Maternal Mortality Ratio (MMR): It was reduced to 100/100,000 in 2012 from 301 in 2001. This could be achieved due to promotion of more institutional deliveries by ASHA workers.

Total Fertility Rate (TFR): This was reduced from 2.9 in 2005 to 2.1 in 2012. 14 states are below the replacement level.

\section{Conclusion}

ASHA becomes an inevitable component in providing primary health care to the village level by creating awareness on health and its social determinants. They have mobilized the community towards local health planning that increased utilization of primary health care and thus placed the health in the hands of the people. Finally, recognizing ASHAs and giving them a greater role in activism and advocacy would provide them with greater recognition in their communities. They play a potential role in providing primary health care at the village level. More than 6 years after the launch of the NRHM, the ASHA has emerged as a significant actor in improving the health situation especially among women and children. Further improving and strengthening of the programme can bring India's targets closer to MDG.

\section{References}

1. WHO, UNICEF, UNFPA, TheWorld Bank (2012) Trends in maternal mortality: 1990 - 2010. Geneva, World Health Organization.

2. Government of India, Ministry of Health \& Family Welfare (2006) About ASHA.

3. Government of India, National Rural Health Mission (2005 -12) Mission Document.

4. Government of India (2010) Annual report, New Delhi: Ministry of Health and Family Welfare.
5. Government of India (2013) National Rural health Mission. All India Executive Summary.

6. Gupta A (2010) Health System Strengthening under NRHM in India.

7. IFPS Technical Assistance Project (ITAP) (2012) Community-based workers improve health outcomes in Uttarakhand, India.

8. Bajpai N, Dholakia RH (2011) Improving the Performance of Accredited Social Health Activists in India. Working Paper No. 1, Working Paper Series, Columbia Global Centres.

9. Government of India (2005) Accredited Social Health Activist (ASHA) guidelines, National Rural Health Mission. New Delhi: Ministry of Health and Family Welfare.

10. Bajpai N, Dholakia RH (2011) Improving the Performance of Accredited Social Health Activists in India. New York: Columbia University.

11. Gopalan SS, Mohanty S, Das A (2012) Assessing community health workers' performance motivation: a mixed-methods approach on India's Accredited Social Health Activists (ASHA) programme. BMJ Open 2.

12. Government of India. National Rural health Mission. Five years of NRHM

13. State Institute of Health \& Family Welfare, Jaipur (2008) Accredited Social Health Activist (ASHA). (Online) 2008.

14. Jain N, Srivastava NK, Khan AM, Dhar N, Adhish V, et al. (2008) Assessment of the functioning of ASHAs under NRHM in Uttar Pradesh. Health and Population: Perspectives and Issues 31: 132-140.

15. Development and Research Services Ltd. (2009) Concurrent Assessment of JananiSurakshaYojana Scheme in Selected States of India, 2008.

16. Bang A (2010) ASHA Training Modules 6 and 7.

17. Haider S, Adhish SV, Gupta S, Dhar N, Datta U, et al. (2008) A rapid appraisal of SAHIYA (ASHA) in Jharkhand. Health and Population: Perspectives and Issues 31: 80-84.

18. Singh MK, Singh JV, Ahmad N, Kumari R, Khanna A (2010) Factors Influencing Utilization of ASHA Services under NRHM in Relation to Maternal Health in Rural Lucknow. Indian Journal of Community Medicine 35: 414-419.

19. Saji JN (2013) Decentralized health care and role of ASHA workers. VISTAS 2: $43-48$.

20. Sightsavers in India. Annual Review (2011). 